\title{
The Human Heart \\ Penny Gray-Allan Memorial Submission
}

\section{Sandra Jenneson*}

\section{THE HUMAN HEART}

A bird's eye view of an emergency department Is like an ant-hill: teamwork, bustle.

The foundation composed not of sand

But our heart muscle. It never stops beating.

Flies on the wall see this muscle.

See shifts so busy they seem endless.

Never busy enough to give an extra meal to Stan.

Stan is homeless. The heart warms.

Maybe this is his only meal today.

A tumor is seen on a CT. The heart sinks.

It's Derek, the 76-year-old who remembered my name.

Now I have to think.
Think about how to be gentle in talking about cancer.

Is it possible? A tough feat.

But I will sit on his bed and not stand at the curtain.

The heart skips a beat.

Somebody's mother Ruth; her heart stopped. Arrest. The monotone of asystole.

Running the code is driven by belief

Of Ruth once again speaking to her family.

In an emergency department, the heart never stops beating.

One stops, another begins. Irrespective of our role. Whether we be patient or doctor, it's a muscle that drives us

To care from our soul.

From the *Department of Emergency Medicine, University of British Columbia.

Correspondence to: Dr. Sandra Jenneson, Department of Emergency Medicine, University of British Columbia, Vancouver, BC; sandraj@ interchange.ubc.ca.

This article has been peer reviewed. 